\title{
Procaspase 8 overexpression in non-small-cell lung cancer promotes apoptosis induced by FLIP silencing
}

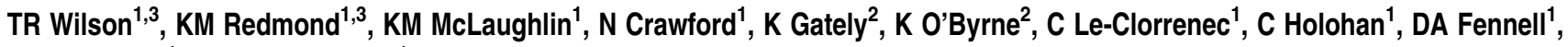 \\ PG Johnston ${ }^{1}$ and DB Longley ${ }^{*, 1}$
}

We found that procaspase 8 was overexpressed in non-small-cell lung cancers (NSCLCs) compared with matched normal tissues. The caspase 8 inhibitor FLICE-inhibitory protein (FLIP) was also overexpressed in the majority of NSCLCs. Silencing FLIP induced caspase 8 activation and apoptosis in NSCLC cell lines, but not in normal lung cell lines. Apoptosis induced by FLIP silencing was mediated by the TRAIL death receptors DR4 and DR5, but was not dependent on ligation of the receptors by TRAIL. Furthermore, the apoptosis induced by FLIP silencing was dependent on the overexpression of procaspase 8 in NSCLC cells. Moreover, in NSCLC cells, but not in normal cells, FLIP silencing induced co-localization of DR5 and ceramide, and disruption of this co-localization abrogated apoptosis. FLIP silencing supra-additively increased TRAIL-induced apoptosis of NSCLC cells; however, normal lung cells were resistant to TRAIL, even when FLIP was silenced. Importantly, FLIP silencing sensitized NSCLC cells but not normal cells to chemotherapy in vitro, and silencing FLIP in vivo retarded NSCLC xenograft growth and enhanced the anti-tumour effects of cisplatin. Collectively, our results suggest that due to frequent procaspase 8 overexpression, NSCLCs may be particularly sensitive to FLIP-targeted therapies.

Cell Death and Differentiation (2009) 16, 1352-1361; doi:10.1038/cdd.2009.76; published online 19 June 2009

Death receptors such as the TRAIL receptors DR4 and DR5 regulate the extrinsic apoptotic pathway. ${ }^{1}$ Classically, activation of death receptors occurs through ligand binding, resulting in recruitment of Fas-associated death domain (FADD), which in turn recruits inactive procaspase 8 (FLICE). ${ }^{2,3}$ The resulting complex is termed the deathinducing signaling complex (DISC). At the DISC, procaspase 8 is activated and subsequently activates executioner caspases 3 and 7, resulting in apoptosis. FLICE-inhibitory protein (FLIP) is a caspase 8 inhibitor and is predominantly expressed as long (FLIP $)$ and short $\left(F_{L} P_{S}\right)$ splice forms. ${ }^{4}$ Both FLIP splice forms are recruited to the DISC, preventing the full activation of caspase 8 , thereby inhibiting apoptosis. ${ }^{5}$ FLIP has been found to be overexpressed in a number of cancers. ${ }^{6,7}$ Although FLIP mRNA expression was found to be more highly expressed in squamous non-small-cell lung cancer (NSCLC) tissues compared with normal tissue, ${ }^{8}$ no difference in expression of FLIP $\mathrm{L}$ protein was observed between matched tumor and normal tissues. ${ }^{9}$

Non-small-cell lung cancer accounts for $\sim 80 \%$ of lung cancer and is responsible for over one million mortalities worldwide each year..$^{10}$ Platinum-based therapies are used in early, locally advanced and metastatic disease; however median survival times are only 8-10 months in the latter setting, and the objective tumor response rate after second line therapy is below $10 \%$. Clearly, new strategies are needed to treat this disease. DR5 has been reported to be over- expressed in a high percentage of primary and metastatic NSCLC. ${ }^{11}$ Unlike many SCLCs, in which the caspase 8 gene is frequently silenced by methylation, NSCLCs typically retain caspase 8 expression. ${ }^{12,13}$ In this report, we show that procaspase 8 and FLIP are frequently overexpressed in NSCLCs and that this preferentially sensitizes NSCLC cells to apoptosis induced by FLIP silencing.

\section{Results}

Differential expression of procaspase 8 and FLIP in NSCLC versus normal tissue. We analyzed procaspase 8 and FLIP expression in a panel of matched normal and tumor tissues from 20 patients with NSCLC (Figure 1a). Expression of the long form of FLIP (FLIP $\mathrm{L}$ ) was comparable in tumor and matched normal tissues for most patients, although 5/20 $(25 \%)$ expressed higher FLIP $P_{L}$ in the tumor tissue (Figures 1a and b). In 13/20 (65\%) patients, expression of the short form of FLIP (FLIPS) was significantly higher in the tumor than the matched normal tissues (Figures 1a and b). Most notably, $17 / 20(85 \%)$ of the tumors had higher procaspase 8 expression in tumor compared with matched normal tissues (Figures 1a and b). There were no obvious correlations between procaspase 8 or FLIP expression and any clinicopathological details (Table 1). FLIP was overexpressed only in tumor tissue that also overexpressed

\footnotetext{
${ }^{1}$ Drug Resistance Laboratory, Centre for Cancer Research and Cell Biology, Queen's University Belfast, Belfast, Northern Ireland, UK and ${ }^{2}$ Department of Cardiothoracic Surgery, St. James's Hospital, Dublin, Ireland

*Corresponding author: DB Longley, Centre for Cancer Research and Cell Biology, Queen's University Belfast, 97 Lisburn Road, Belfast, BT9 7BL, UK.

Tel: + 442890 972647; Fax: + 442890 972776, E-mail: d.longley@qub.ac.uk

${ }^{3}$ These authors contributed equally to this work

Keywords: NSCLC; FLIP; caspase 8; chemotherapy; TRAIL

Abbreviations: FADD, Fas-associated death domain; FLICE, inactive procaspase 8; DISC, death-inducing signaling complex; FLIP, FLICE-inhibitory protein; FLIPL, long splice forms; FLIPs, short splice forms; NSCLC, non-small-cell lung cancer

Received 05.2.09; revised 14.5.09; accepted 21.5.09; Edited by C Duckett; published online 19.6.09
} 
a
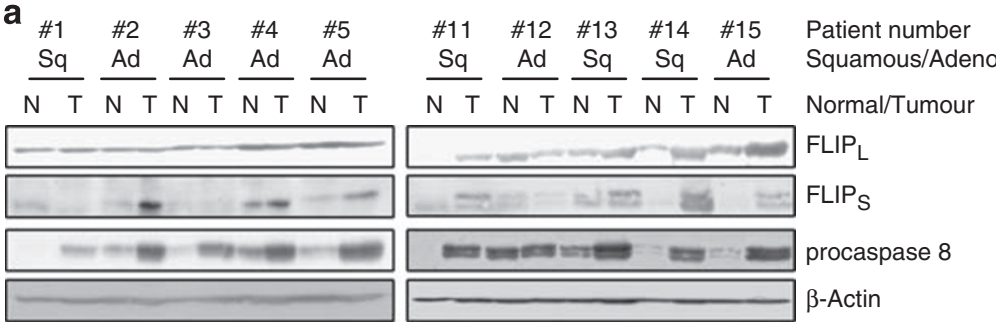

C

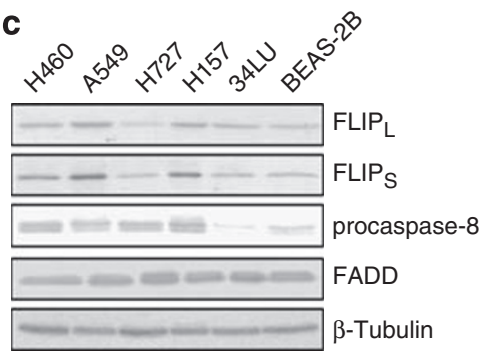

d

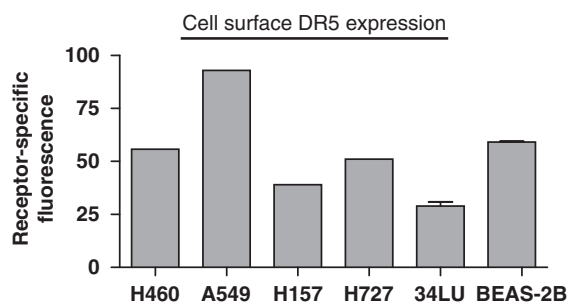

b

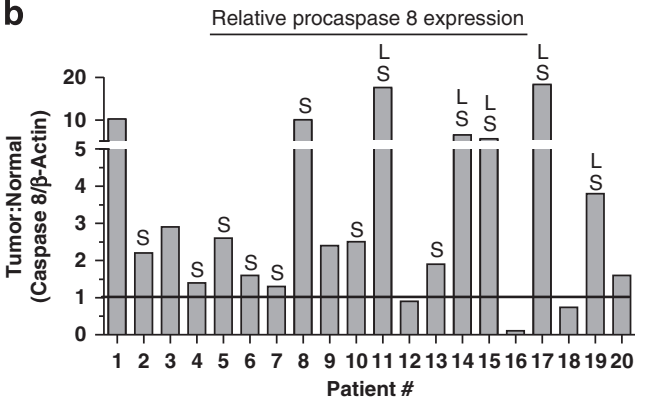

Figure 1 Expression of death receptor-signaling molecules in non-small-cell lung cancer (NSCLC) tumors and cell lines. (a) Western blot showing FLIPL, FLIPS and procaspase 8 expression in matched NSCLC (T) and normal (N) tissues. Equal loading was assessed by analyzing $\beta$-actin expression. (b) Densitometry analysis of the relative expression of procaspase 8 in matched tumor and normal tissues. Tumors, which also overexpressed FLIP $P_{L}$ and FLIPS are indicated by $L$ and $S$, respectively. (c) Western blot showing FLIP, FLIPS, caspase 8 and Fas-associated death domain (FADD) expression in NSCLC (H460, A549, H157 and H727) and normal lung (34LU and BEAS-2B) cell lines. (d) Cell surface expression of DR4 and DR5 in NSCLC and non-cancer lung cell lines. Expression was compared with an isotype control antibody

Table 1 Clinicopathological details of the NSCLC patients

\begin{tabular}{|c|c|c|c|c|c|}
\hline Patient no. & $M / F$ & Adeno/squamous & Age & Stage & Surgery date \\
\hline 1 & Male & Squamous & 66 & IB & 23.1 .06 \\
\hline 2 & Male & Adenocarcinoma & 73 & IB & 22.1 .05 \\
\hline 3 & Female & Adenocarcinoma & 56 & IA & 27.9 .04 \\
\hline 4 & Male & Adenocarcinoma & 79 & IIIB & 16.1.06 \\
\hline $5^{a}$ & Female & Adenocarcinoma & 32 & IIIA & 7.11 .05 \\
\hline 6 & Female & Squamous & 57 & $\mathrm{IB}$ & 30.1 .06 \\
\hline 7 & Male & Squamous & 64 & IIIB & 16.3.06 \\
\hline 8 & Male & Adenocarcinoma & 75 & IIB & 16.1 .06 \\
\hline 9 & Male & Squamous & 49 & IB & 19.12 .05 \\
\hline 10 & Male & Squamous & 68 & IIIB & 22.04 .05 \\
\hline $11^{\mathrm{a}}$ & Male & Squamous & 79 & IIIB & 7.7.06 \\
\hline 12 & Female & Adenocarcinoma & 54 & IB & 11.7 .06 \\
\hline 13 & Male & Squamous & 62 & IB & 14.7.06 \\
\hline 14 & Male & Squamous & 73 & IIB & 20.6 .06 \\
\hline 15 & Male & Adenocarcinoma & 81 & IA & 4.7 .06 \\
\hline 16 & Male & Adenocarcinoma & 67 & IA & 5.5 .06 \\
\hline 17 & Female & Adenocarcinoma & 61 & IIB & 2.5 .06 \\
\hline $18^{\mathrm{a}}$ & Female & Adenocarcinoma & 73 & IIIA & 14.7 .06 \\
\hline 19 & Male & Adenocarcinoma & 79 & IIIB & 9.1 .06 \\
\hline 20 & Female & Adenocarcinoma & 71 & $\| A$ & 13.7 .05 \\
\hline
\end{tabular}

Samples from these patients were used to examine FLIP, procaspase 8, DR4 and DR5 expression in matched normal and tumour tissues (Figures 1a and b and

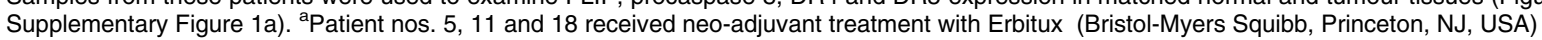

procaspase 8, although not all procaspase 8-overexpressing tumors overexpressed FLIP (Figure 1b). We also examined DR4 and DR5 expression in the patient samples (Supplementary Figure 1a). Of note, DR4 and DR5 were expressed in every tumor sample. Moreover, DR4 and DR5 expression were similar in the majority of matched normal and tumor tissues, although $5 / 20$ patients actually expressed higher levels of DR4 and/or DR5 in their tumors, and one patient (\#12) had lower DR4 and DR5 in their tumor.
Procaspase 8 overexpression in NSCLCs suggested that these tumors may be sensitive to caspase 8-mediated apoptosis. To assess this in vitro, we used four NSCLC and two non-cancer 'normal' lung cell lines. The H460 large cell lung cancer cell line, the A549 adenocarcinoma cell line, the H157 squamous cell line and the H727 carcinoid cell line all expressed higher levels of procaspase 8 compared with the non-cancer 34LU lung fibroblast and BEAS-2B bronchial epithelial cell lines (Figure 1c). Apart from the H727 cell line, 
the NSCLC cell lines expressed higher levels of FLIPS (Figure 1c). FLIP $P_{L}$ expression was higher in A549 cells compared with the other cell lines, whereas FADD was expressed at similar levels in the panel. Overall, the patterns of FLIP and procaspase 8 expression in the tumor and normal cell line models were similar to those observed in the clinical samples. Of note, caspase 8 gene expression in the cell line panel did not correlate with procaspase 8 protein expression (Supplementary Figure 1c), indicating that overexpression of procaspase 8 in the NSCLC cell lines is because of posttranscriptional regulation.

The cancer and normal cell line models expressed similar levels of cell surface DR5, with the exception of A549 cells, which expressed significantly higher levels (Figure 1d). Moreover, western blot analyses indicated overall that, the relative expression of DR5 in the normal and tumor cell line models was similar to the pattern of expression observed in the majority of matched normal and tumor samples (Supplementary Figure 1a). H460 and A549 cells expressed high levels of DR4 on the cell surface; H157 cells expressed moderate levels and $\mathrm{H} 727$ cells expressed low levels. DR4 cell surface expression was barely detectable in the 34LU and BEAS-2B cell lines. By western blot analysis, DR4 was also expressed at a lower level in the BEAS-2B cells compared with the $\mathrm{H} 460$ cells (Supplementary Figure 1a). A549 and 34LU cells expressed relatively high levels of Fas, whereas the other cell lines expressed lower levels (Supplementary Figure 1b).
NSCLC cells are more sensitive to FLIP silencing than normal lung cells. The FLIP gene silencing induced cell death in the absence of death ligand co-treatment in NSCLC cells (Figure $2 a$ and $b$ ). Western blot analyses indicated that FLIP downregulation correlated with increasing PARP cleavage and caspase 8 activation (Figure 2a). Similar results were obtained in $\mathrm{H} 157$ and $\mathrm{H} 727$ cells (data not shown). To assess the relative importance of the FLIP splice

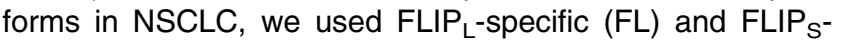
specific (FS) siRNAs. Compared with the dual targeted FLIP siRNA, little or no caspase activation or PARP cleavage was observed in cells that had been transfected with either of the splice form-specific siRNAs (Figure 2c). Despite successful knockdown of FLIP, no PARP cleavage, caspase 8 activation (Figure 2d and Supplementary Figure 1d) or apoptosis (Figure 2b) were observed in BEAS-2B or 34LU cells transfected with FLIP siRNA. Collectively, these results indicate that silencing both main FLIP splice forms induces caspase activation and cell death in NSCLC, but not in the normal lung cells.

Role of death receptors in regulating apoptosis after FLIP silencing. To analyze the roles of the TRAIL and Fas receptors in regulating FLIP siRNA-induced apoptosis, specific siRNAs were used to specifically decrease expression of each receptor (Supplementary Figure $2 a$ and b). Downregulating DR4 or DR5 alone significantly reduced cell a

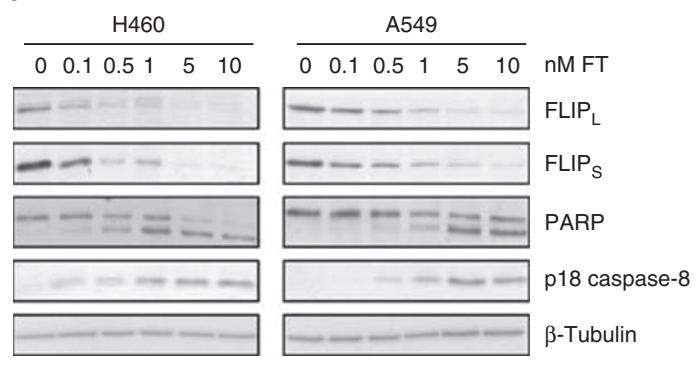

C

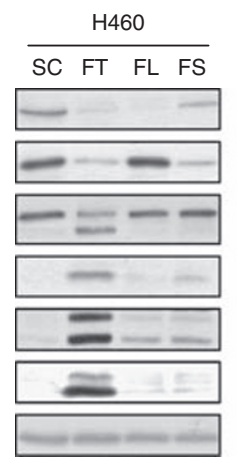

b

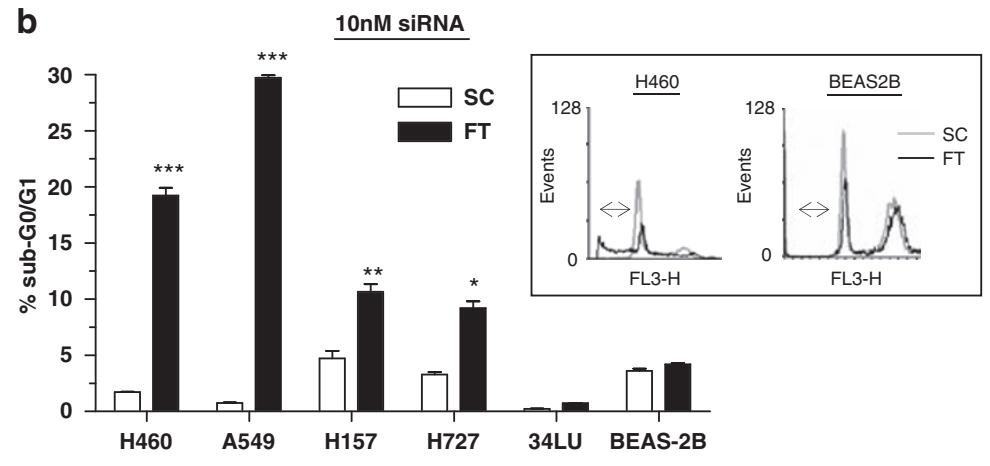

d

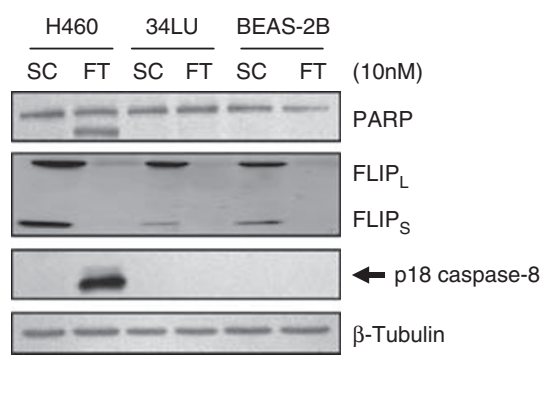

Figure 2 Effect of FLIP silencing on apoptosis. (a) FLIP $P_{L}$ and FLIPS expression, caspase 8 activation (as shown by generation of the active p18-subunit) and PARP cleavage analysis in $\mathrm{H} 460$ and A549 cells transfected with FLIP-targeted (FT) siRNA for $24 \mathrm{~h}$. (b) Flow cytometry analysis of apoptosis in non-small-cell lung cancer (NSCLC) and normal lung cell lines transfected with $10 \mathrm{nM} \mathrm{SC}$ or FT siRNA for $48 \mathrm{~h}$. Apoptosis was assessed by analyzing the sub-G0/G1 fraction of cells. (*** denotes $P<0.001$, ${ }^{* *}$ denotes $P<0.01$, * denotes $P<0.05$; Student's $t$-test). Inset: representative histograms showing the relative effects of $\mathrm{FT}$ siRNA on the cell cycle profiles of H460 and BEAS-2B cells. The sub-G0/G1 apoptotic region is indicated by the arrows. (c) FLIP expression, caspase 8, 9 and 3 activation and PARP cleavage analysis in H460 and A549

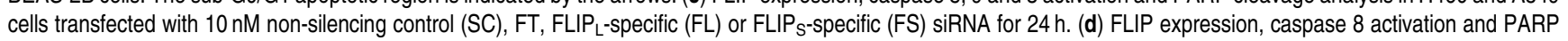
cleavage analysis in H460, 34LU and BEAS-2B cells transfected with $10 \mathrm{nM} \mathrm{SC}$ or FT siRNA for $24 \mathrm{~h}$ 
a
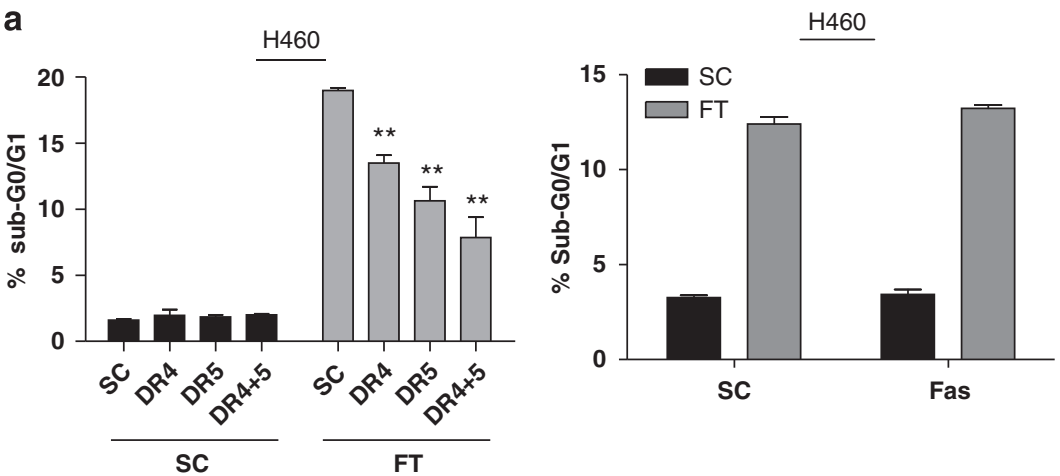

b

c
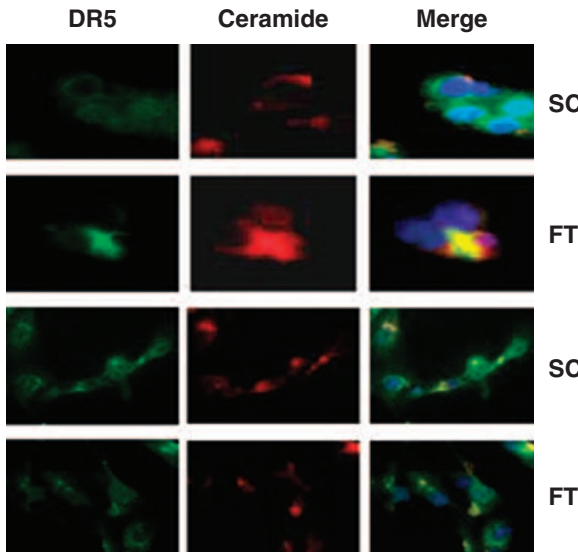

d SC
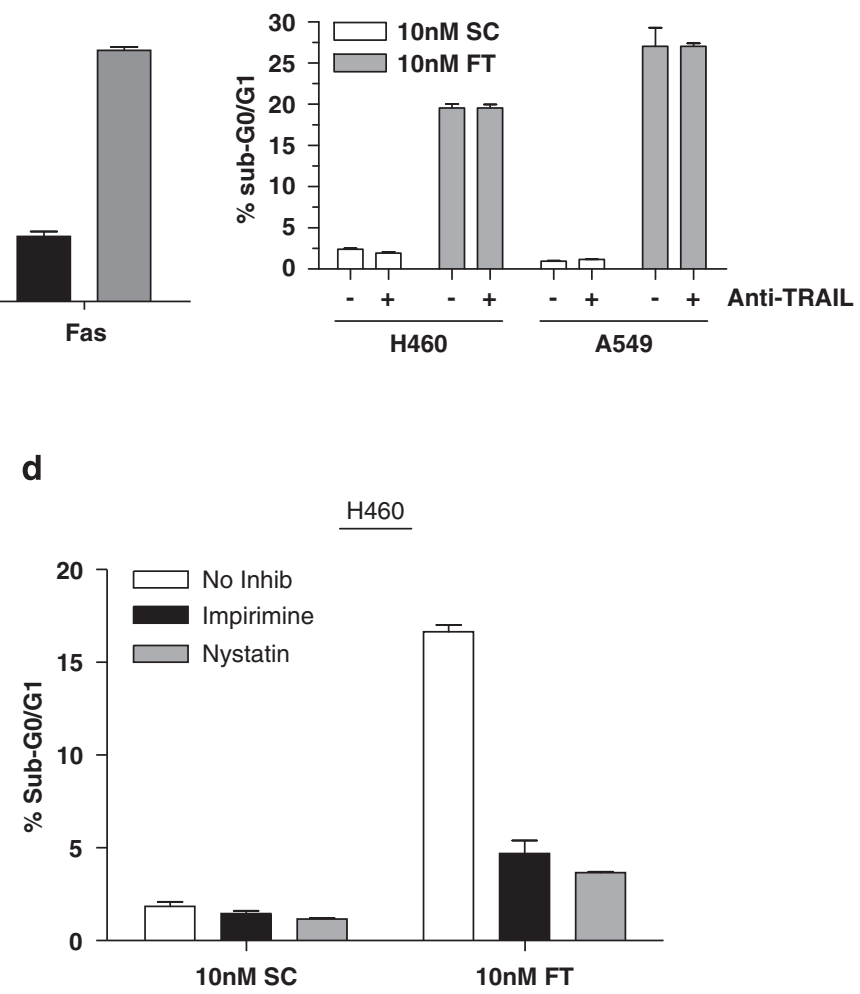

Figure 3 Death receptor involvement in apoptosis induced by FLIP silencing. (a) Flow cytometry analysis of apoptosis in H460 cells transfected with $10 \mathrm{nM}$ non-silencing control (SC) or FLIP-targeted (FT) siRNA for $24 \mathrm{~h}$. Cells were pre-transfected for $24 \mathrm{~h}$ with $10 \mathrm{nM}$ DR4, DR5, DR4 + DR5, or Fas siRNAs as indicated (Student's t-test; ${ }^{* * *}$ denotes $P<0.001$, ${ }^{* *}$ denotes $P<0.01$ ). (b) Flow cytometry analysis of apoptosis in $\mathrm{H} 460$ and A549 cells transfected with $10 \mathrm{nM} \mathrm{SC}$ or FT siRNAs for $24 \mathrm{~h}$. Cells were cotreated with a TRAIL-neutralizing antibody (Anti-TRAIL; $100 \mu \mathrm{g} / \mathrm{ml}$ ) as indicated. (c) Immunostaining of DR5 (green), ceramide (red) and nucleus (blue) in H460 and BEAS-2B cells transfected with $10 \mathrm{nM}$ non-silencing control (SC) or FLIP-targeted (FT) siRNA for $16 \mathrm{~h}$, as analyzed by fluorescent microscopy. (d) Flow cytometry analysis of apoptosis in $\mathrm{H} 460$ cells transfected with $10 \mathrm{nM}$ non-silencing control (SC) or FLIP-targeted (FT) siRNA for $24 \mathrm{~h}$ and co-treated $20 \mu \mathrm{g} / \mathrm{ml}$ Nystatin or $50 \mu \mathrm{M}$ Imipramine

death after FLIP silencing in H460 cells, and simultaneously downregulating both DR4 and DR5 had a further protective effect (Figure 3a). In contrast, silencing Fas had no effect on FLIP siRNA-induced apoptosis (Figure 3a). Similar results were observed in the A549 cell line (data not shown). Activation of DR4 and DR5 classically occurs after TRAIL binding; however, expression of membrane-bound TRAIL was very low $(\sim 1.5 \%$ or less compared to isotype control, data not shown) in the NSCLC cell lines, and neither TRAIL siRNA (data not shown) nor TRAIL-neutralizing antibodies abrogated FLIP silencing-induced cell death (Figure $3 \mathrm{~b}$ and Supplementary Figure 2c). Collectively, these results suggest that apoptosis induction after FLIP silencing is mediated through DR4 and DR5, but is not dependent on ligation of these receptors by TRAIL.

TRAIL can induce super clustering of TRAIL receptors into ceramide-containing lipid rafts. ${ }^{14}$ Furthermore, it was shown that TRAIL-induced generation of ceramide and formation of DR5-containing ceramide-enriched membrane domains is dependent on acid sphingomyelinase (ASM) and is necessary for the induction of TRAIL-induced apoptosis. In H460 cells, FLIP silencing resulted in the formation of intense foci on the cell surface, at which ceramide and
DR5 were co-localized (Figure 3c). In contrast, the patterns of ceramide and DR5 expression were similar in control and FLIP siRNA-transfected BEAS-2B cells, indicating that DR5 and ceramide failed to cluster after FLIP silencing in this normal cell model. These results suggest that silencing FLIP preferentially induces TRAIL receptor clustering in cancer cells compared with normal cells. To examine whether the formation of DR5-containing lipid rafts was necessary $f$ or apoptosis induced by FLIP silencing, we used Nystatin, a cholesterol-depleting agent that has been shown to inhibit the redistribution of TRAIL receptors into lipid rafts. ${ }^{15}$ We also investigated the role of ASM in FLIP siRNA-induced apoptosis using the ASM inhibitor imipramine. Notably, Nystatin and imipramine both inhibited FLIP siRNA-induced apoptosis in $\mathrm{H} 460$ cells (Figure $3 \mathrm{~d}$ ). Similar results were obtained in A549 cells (data not shown). These results suggest that after FLIP silencing in NSCLC cells, ceramideenriched DR5-containing platforms are formed, and that the formation of these platforms is necessary for the induction of apoptosis. Furthermore, the failure to induce clustering of DR5 into ceramide-enriched lipid rafts may explain the resistance of BEAS-2B cells to apoptosis induced by FLIP siRNA. 
Role of procaspase 8 and BID in regulating apoptosis after FLIP silencing. To further determine the mechanism of FLIP silencing-induced apoptosis, we examined the role of procaspase 8 expression. Downregulating procaspase 8 by $\sim$ threefold in $\mathrm{H} 460$ cells (to levels approaching the constitutive level of expression in BEAS-2Bs) was sufficient to abrogate apoptosis induced by both FLIP silencing (Figure $4 \mathrm{a}$ and b) and TRAIL (Supplementary Figure 2d), indicating that the expression level of procaspase 8 is a critical determinant of both FLIP siRNA- and TRAIL-induced apoptosis. In support of this, upregulating procaspase 8 expression by $\sim$ threefold in BEAS2B cells using interferon- $\gamma$ (a known activator of caspase 8 transcription $^{8}$ ) sensitized BEAS-2B cells to apoptosis induced by FLIP silencing and TRAIL (Figure 4c). Dependence on caspase 8 for this sensitization was shown by its abolishment in the presence of caspase 8-targeted siRNA.

Cross-talk between the extrinsic and intrinsic apoptotic pathways is mediated by Bid, which, when cleaved by caspase 8 , translocates to the mitochondria and promotes the release of pro-apoptotic factors. ${ }^{16}$ Silencing Bid completely abrogated FLIP siRNA-induced apoptosis in the A549 cell line, but only partially attenuated apoptosis in the $\mathrm{H} 460$ cell line (Figure 4d). These results indicate that the A549 cells must amplify the apoptotic signal through the mitochondria and behave like type II cells after FLIP silencing, whereas the
H460 cells behave more like type I cells. ${ }^{17}$ Thus, FLIP silencing has the potential to activate apoptosis in both type I and II NSCLC cells.

FLIP siRNA sensitizes NSCLC but not normal lung cells to TRAIL. The H460 cell line was highly sensitive to TRAILinduced cell death, whereas the A549, H727 and H159 cell lines were less sensitive (Figure 5a). The two normal lung cell lines were completely resistant to TRAIL-induced caspase 8 activation and apoptosis (Figure 5a). FLIP silencing synergistically increased TRAIL-induced apoptosis in all the NSCLC cell lines (Figure 5b); similar results were observed for the Fas agonistic antibody $\mathrm{CH}-11$ (Figure 5c). Interestingly, the 34LU and BEAS-2B cell lines were not sensitized to TRAIL or $\mathrm{CH}-11$ treatment after transfection with FLIP siRNA. Furthermore, TRAIL treatment alone and combined treatment with FLIP siRNA and TRAIL both failed to activate caspase 8 in the BEAS-2B cell line (Figures $5 d$ and Supplementary Figure 1d). Thus, in contrast to the NSCLC cells, FLIP does not seem to be a critical determinant of TRAIL sensitivity in the normal lung cell line models. In addition, we found that TRAIL-induced apoptosis in the presence and absence of FLIP siRNA co-treatment could be equally mediated by either DR4 or DR5, as only simultaneous silencing of both receptors blocked apoptosis (Supplementary Figures 2d and e). a

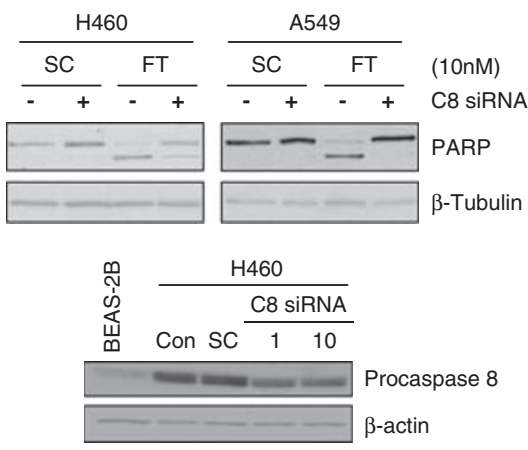

b

b $\mathrm{H} 460$
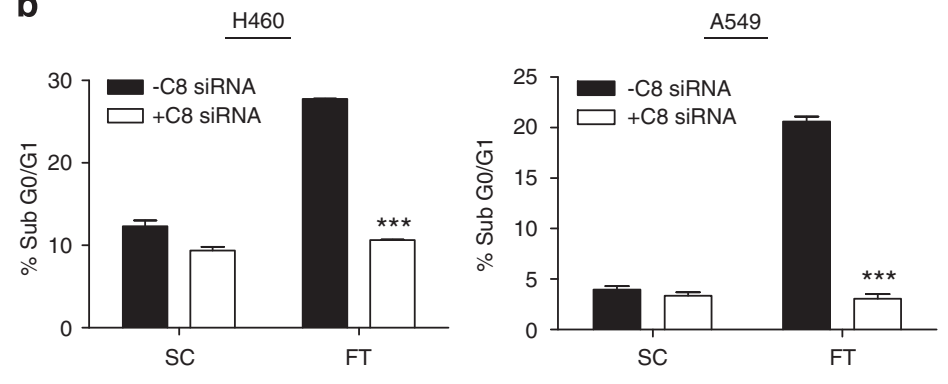
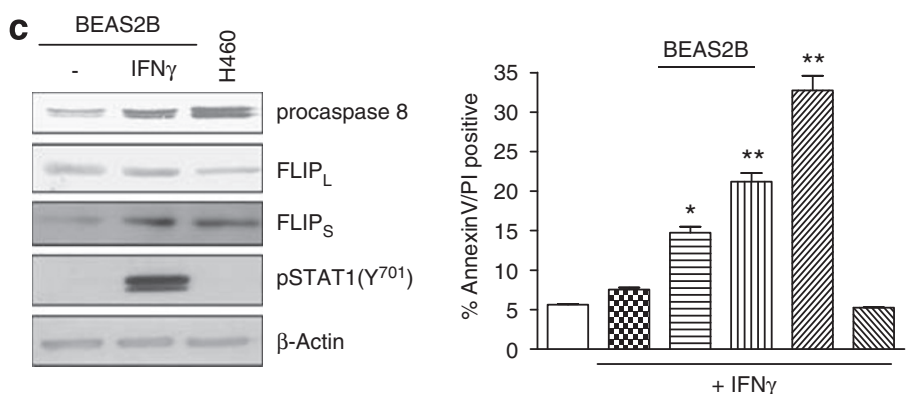

$\square$ Control

$\operatorname{LCO}$

$\sqsupseteq \mathrm{FT}$

mIm SC+TRAIL

mins FT+TRAIL

C8si+FT+TRAIL
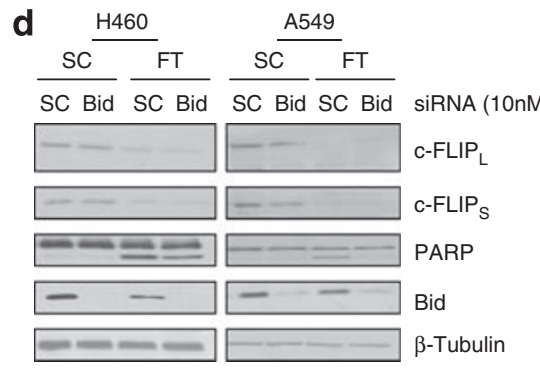

Figure 4 Roles of caspase 8 and BID in apoptosis induced by FLIP silencing. (a) Western blot analysis of PARP cleavage in H460 cells transfected with $10 \mathrm{nM}$ SC or FT siRNAs for $24 \mathrm{~h}$. Cells were pre-transfected for $24 \mathrm{~h}$ with $10 \mathrm{nM}$ caspase 8 (C8)-targeted siRNA. (lower panel) Western blot analysis of procaspase 8 expression in $\mathrm{H} 460 \mathrm{cells}$ transfected with no siRNA (Con), 1 and $10 \mathrm{nM} \mathrm{C8}$ siRNA and $10 \mathrm{nM}$ control siRNA (SC); expression was compared with baseline expression in BEAS-2B cells. (b) Flow cytometry analysis of apoptosis in $\mathrm{H} 460$ cells transfected with $10 \mathrm{nM} \mathrm{SC}$ or FT siRNAs for $24 \mathrm{~h}$. Cells were pre-transfected for $24 \mathrm{~h}$ with $10 \mathrm{nM}$ caspase 8 (C8) targeted siRNA. (Student's $t$-test; ${ }^{* * *}$ denotes $P<0.001$ ). (c) (Western blot) Procaspase 8 expression and STAT- 1 activation in BEAS-2B cells treated with $1000 \mathrm{U} / \mathrm{ml}$ IFN $\gamma$; expression of procaspase 8 was compared with constitutive expression in $\mathrm{H} 460$ cells. (Graph) Flow cytometry analysis of apoptosis in BEAS-2B cells transfected with $10 \mathrm{nM} \mathrm{SC}$ or FT siRNAs and treated with $1000 \mathrm{U} / \mathrm{ml} \mathrm{IFN} \gamma$ and $5 \mathrm{ng} / \mathrm{ml}$ TRAlL for $24 \mathrm{~h}$. Cells were pre-transfected with $10 \mathrm{nM} \mathrm{C8}$ siRNA as indicated (Student's $t$-test; ${ }^{*}$ denotes $P<0.05$ $(P=0.011)$, ${ }^{*}$ denotes $\left.P<0.01\right)$. (d) Western blot analysis of PARP cleavage, FLIP and BID expression in H460 and A549 cells transfected with $10 \mathrm{nM}$ SC or FT siRNAs for $24 \mathrm{~h}$. Cells were pre-transfected with $10 \mathrm{nM} \mathrm{SC}$ or BID siRNAs for $24 \mathrm{~h}$ as indicated 

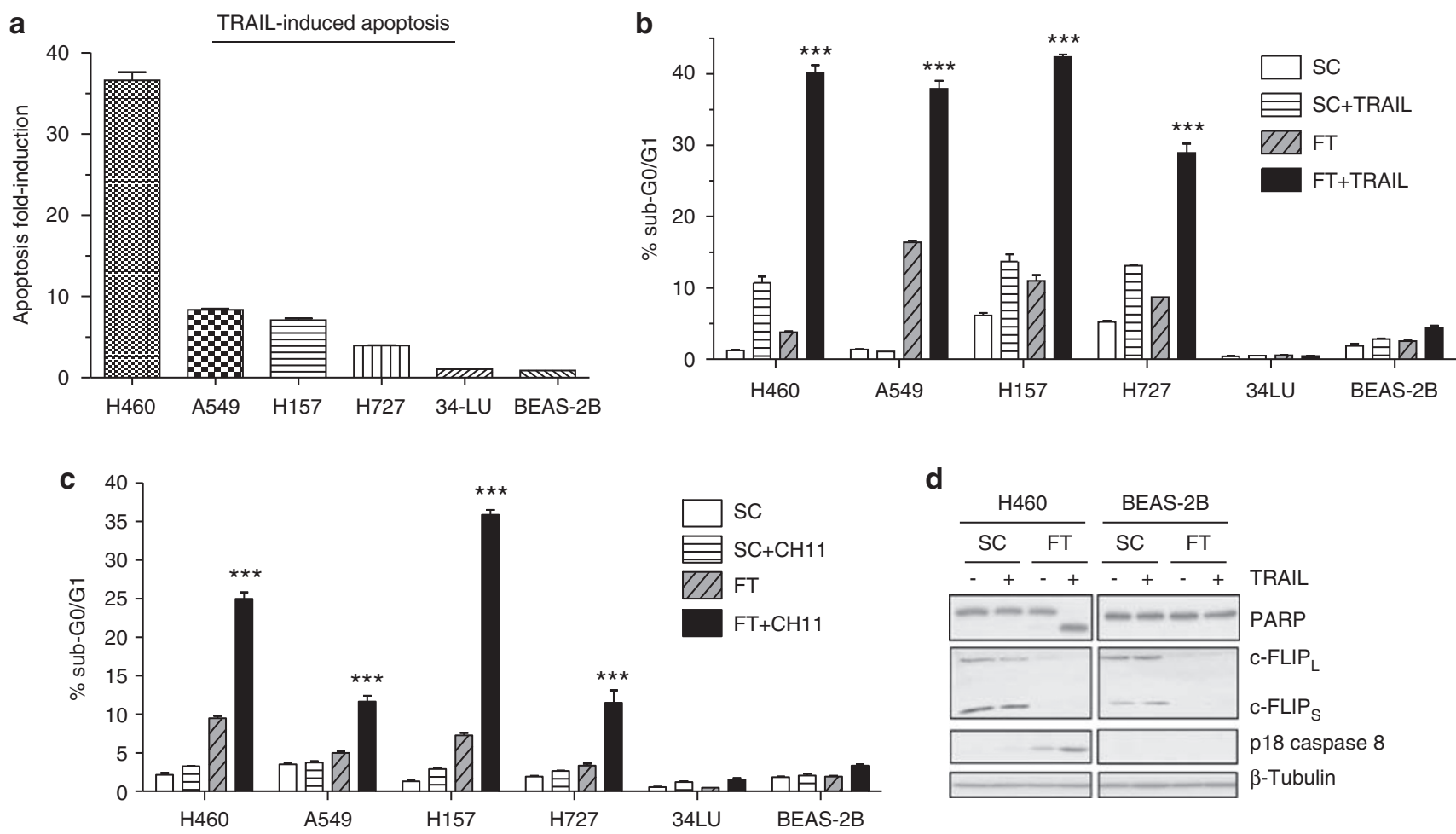

Figure 5 Effect of FLIP silencing on TRAIL and Fas-induced apoptosis in vitro. (a) Flow cytometry analysis showing the relative induction of apoptosis in non-small-cell lung cancer (NSCLC) and normal lung cell lines after TRAIL treatment (50 ng/ml). Apoptosis was assessed by analyzing the sub-G0/G1 population of cells, and the foldinduction of apoptosis was calculated compared with the control cells. (b) and (c) Flow cytometry analysis of apoptosis in NSCLC and non-cancer cells transfected with $1 \mathrm{nM}$ non-silencing control (SC) or FLIP-targeted (FT) siRNA for $24 \mathrm{~h}$. Transfected cells were co-treated with $5 \mathrm{ng} / \mathrm{ml}$ TRAlL (b) or $100 \mathrm{ng} / \mathrm{ml}$ of the Fas agonist CH11 (c). Apoptosis was assessed by analyzing the sub-G0/G1 fraction of cells ${ }^{* * *}$ denotes $P<0.001$, two-way ANOVA). (d) Western blot analysis showing FLIP expression, PARP cleavage and caspase-8 activation (active p18-subunit) in H460 and BEAS-2B cells transfected with $1 \mathrm{nM} \mathrm{SC}$ or FT siRNA and co-treated with $5 \mathrm{ng} / \mathrm{ml}$ TRAIL for $24 \mathrm{~h}$. Equal loading was confirmed by analyzing $\beta$-tubulin expression

FLIP siRNA sensitizes NSCLC but not normal lung cells to chemotherapy. Notably, FLIP silencing significantly sensitized the four NSCLC cell lines to cisplatin-induced apoptosis (Figure $6 \mathrm{a}$ and data not shown). Furthermore, similar to the apoptosis induced by FLIP silencing alone, this supra-additive increase in apoptosis was mediated by DR4 and DR5 (Supplementary Figure 2f). However, FLIP siRNA failed to sensitize the $34 \mathrm{LU}$ or BEAS-2B cell lines to cisplatininduced apoptosis (Figure 6b). Similar results were observed with Taxol (Paclitaxel, Mayne Pharma, Warwickshire, UK; Supplementary Figures $3 a$ and $b$ ). We also found that silencing FLIP could overcome drug resistance in a cisplatinresistant $\mathrm{H} 460$ daughter cell line (unpublished observations).

To assess the effects of targeting FLIP in vivo, we used an $\mathrm{H} 460$ xenograft model in Balb/c nude mice. Xenografts that were injected with FLIP siRNA expressed reduced levels of FLIPL and FLIPS compared with SC siRNA-injected xenografts (Figure 6c). Furthermore, caspase 3 activation was observed in FLIP siRNA injected xenografts indicative of enhanced cell death. Importantly, compared with untreated and siRNA controls, xenografts injected with FLIP siRNA grew significantly more slowly (Figure 6c). The in vivo effect of FLIP silencing in combination with cisplatin was also examined. Cisplatin treatment retarded xenograft growth to a very similar extent as FLIP siRNA (Figure 6d). Importantly, the combination of FLIP siRNA and cisplatin further inhibited xenograft growth compared with FLIP siRNA alone or cisplatin alone. Of note, there was almost no tumor growth in FLIP siRNA and cisplatin co-treated mice until after the last day of treatment. These results indicate that downregulating FLIP retarded xenograft growth and enhanced the growth inhibitory effect of cisplatin in vivo.

\section{Discussion}

FLIP protein overexpression has been reported in numerous epithelial cancers. ${ }^{6,7}$ Despite overexpression of FLIP mRNA having been reported in squamous NSCLC, no overexpression of FLIP $\mathrm{L}$ protein was noted in NSCLC tissues. ${ }^{9}$ In this study, we found that FLIP $\mathrm{L}$ protein expression was overexpressed in $5 / 20$ of NSCLCs compared with normal tissues. Furthermore, FLIP was expressed at a higher level in $65 \%$ of NSCLCs. Previous studies have shown that unlike SCLCs, NSCLCs express caspase 8 protein. ${ }^{12,13}$ We found that $17 / 20$ of NSCLCs actually had higher procaspase 8 expression than matched normal tissues, and the extent of overexpression was $>$ two fold for $12 / 20$ patients. Moreover, all but three of the NSCLCs that overexpressed procaspase 8 by $>$ two fold also overexpressed FLIP. Expression of DR4 and DR5 in the NSCLCs were similar to those in the matched normal tissues for $15 / 20$ patients and were actually higher in NSCLCs in the remaining five patients. Tissue microarrays are currently 
a

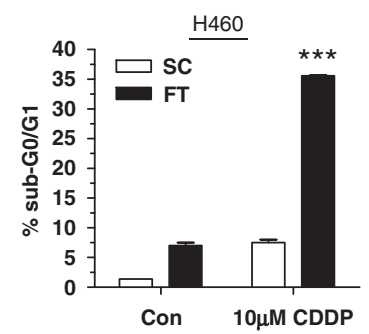

C

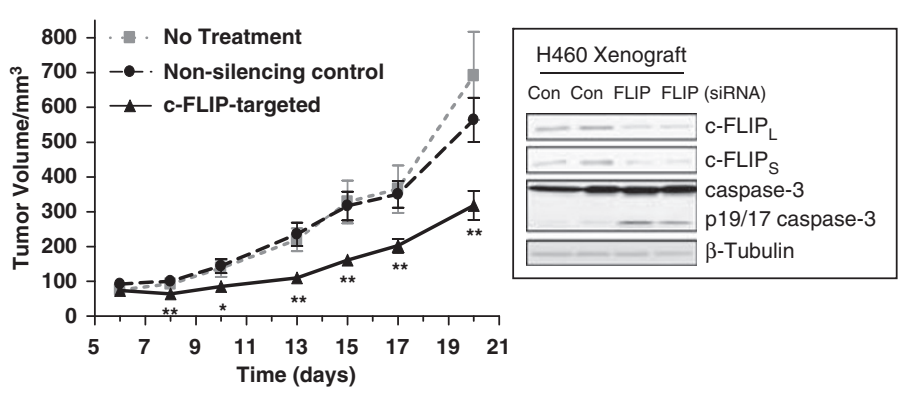

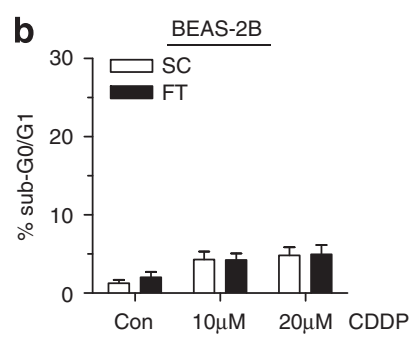
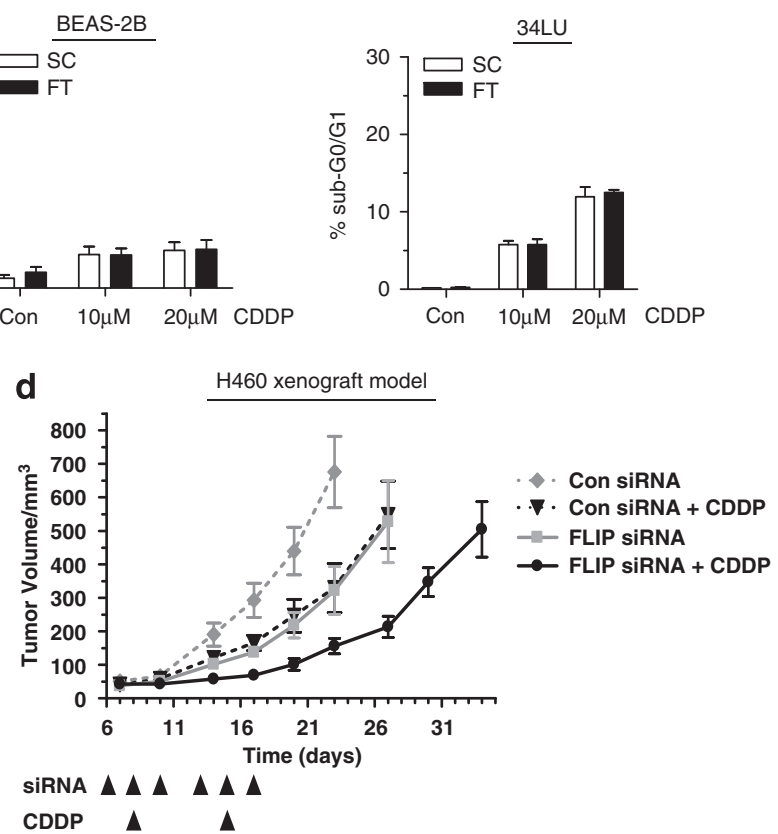

d SIRNA $\triangle \Delta \triangle \Delta \Lambda$

Figure 6 Effect of FLIP silencing on cispatin-induced apoptosis in vitro and in vivo. (a) Flow cytometry analysis of apoptosis in H460 and A549 cells transfected with $1 \mathrm{nM}$ non-silencing control (SC) or FLIP-targeted (FT) siRNAs and treated with cisplatin (CDDP) for $48 \mathrm{~h}$. Combined effects of FLIP siRNA and CDDP were synergistic (*** denotes $P<0.001$; two-way ANOVA). (b) Flow cytometry analysis of apoptosis in BEAS-2B and $34 \mathrm{LU}$ cells transfected with $1 \mathrm{nM} \mathrm{SC}$ or FT siRNAs and treated with cisplatin (CDDP) for $48 \mathrm{~h}$. (c) Growth of $\mathrm{H} 460$ xenografts injected with Stealth modified FLIP or control siRNAs. After implantation (day 0), the xenografts were injected with 1000 pmol siRNA on days $1,3,6,8,10,13,15$ and 17. A no treatment group was included. ( ${ }^{*}$ denotes $P<0.05$; * denotes $P<0.01$; Student's $t$-test). Western blot analysis of FLIP expression and caspase 3 activation in $\mathrm{H} 460$ xenografts injected with $1000 \mathrm{pmol}$ control (Con) or FLIP siRNAs for $24 \mathrm{~h}$. (d) Growth of H460 xenografts injected with FLIP or control siRNAs. After tumor establishment (day 6), the xenografts were injected with $1000 \mathrm{pmol}$ siRNA thrice a week for 2 weeks. Mice were treated with cisplatin (CDDP; $5 \mathrm{mg} / \mathrm{kg} ; \mathrm{IP})$ once a week for 2 weeks as indicated

being constructed to assess caspase 8 , FLIP, DR4 and DR5 expression and prognostic relevance in a larger cohort of NSCLC patients by immunohistochemistry. However, our initial western blot analyses prompted us to examine the roles of caspase 8 and FLIP in regulating apoptosis in NSCLC.

We have previously shown that FLIP gene silencing induced caspase 8 activation and apoptosis in colorectal cancer cells and that FLIP $P_{L}$ was the more important splice form for this phenotype..$^{18}$ In the current study, we found that silencing both FLIP $P_{L}$ and FLIP was required for maximal caspase 8, 9 and 3 activation and apoptosis in NSCLC cells. Splice form-specific silencing had only a modest effect on apoptosis in NSCLC cells, suggesting that one splice form can efficiently compensate for loss of the other. Importantly, FLIP gene silencing failed to induce caspase 8 activation and apoptosis in normal lung cell line models. To our knowledge, these are the first studies to suggest that FLIP inhibition preferentially induces apoptosis in cancer cells compared with normal cells.

In agreement with previous studies, ${ }^{19}$ we found that TRAIL treatment induced apoptosis in NSCLC cell lines (albeit to varying degrees), but not in normal lung models. Notably, we found that FLIP silencing potently sensitized each NSCLC cell line to TRAIL, but failed to sensitize the normal lung cells. This suggests that although FLIP clearly plays a key role in regulating the sensitivity of NSCLC cells to TRAIL, it may be less important in normal lung cells. These findings have clinical relevance, as a number of TRAIL receptor-targeted therapeutics are in early phase clinical development. ${ }^{20}$
Furthermore, Schimmer et al. ${ }^{21}$ recently identified a smallmolecule inhibitor of FLIP. Our observations suggest that targeting FLIP may preferentially sensitize NSCLC cells to TRAIL receptor-targeted therapeutics.

Downregulating FLIP has been shown to sensitize colon, ovarian and cervical cancer cells to chemotherapy-induced cell death. ${ }^{22-24}$ We found that silencing FLIP sensitized NSCLC cells to cisplatin- and taxol-induced apoptosis, but failed to sensitize the normal lung cells. Thus, targeting FLIP not only preferentially sensitizes NSCLC cells to death receptor-targeted agents, but also to chemotherapeutic agents commonly used to treat this disease. Importantly, we were able to show that silencing FLIP in vivo retarded NSCLC xenograft growth. Moreover, we showed for the first time that targeting FLIP in vivo can significantly enhance the antitumour effects of chemotherapy. Collectively, these results strongly suggest that FLIP is a key regulator of chemoresistance in NSCLC. Of note, FLIP silencing was able to induce apoptosis in both type I (H460) and type II (A549) NSCLC cells. Moreover, we found that FLIP silencing sensitized both type I and type II NSCLC cells to TRAIL- and chemotherapyinduced apoptosis. Thus, targeting FLIP either alone or in combination with chemotherapy or TRAIL may be a viable therapeutic strategy, regardless of whether the apoptotic signal requires amplification through the intrinsic pathway.

It has been reported that even when both DR4 and DR5 are expressed, only one may function to induce apoptosis. ${ }^{20}$ Using receptor-specific siRNAs, we found that induction of apoptosis after FLIP silencing was mediated by DR4 and 
DR5, but not Fas. Consistent with this, the cell lines, which expressed the highest total levels of DR4 and DR5 were the most sensitive to FLIP siRNA-induced apoptosis. Although the two normal lung cell lines expressed low levels of DR4, it should be noted that FLIP siRNA-induced apoptosis was only partially blocked in NSCLC cells in which DR4 was downregulated, indicating that FLIP silencing can induce apoptosis in cells with low DR4 expression as long as DR5 is expressed. Therefore, lack of DR4 expression cannot explain the complete resistance of the normal lung cell lines to FLIP silencing. Of note, we found that blocking binding of TRAIL to its receptors failed to inhibit FLIP siRNA-induced apoptosis in NSCLC cells, indicating that downregulating FLIP triggers ligand-independent activation of DR4- and DR5-mediated apoptosis. The synergistic interactions between FLIP siRNA and both TRAIL and cisplatin were also found to be mediated through both DR4 and DR5.

Several studies have indicated that after ligation, death receptors cluster into lipid rafts, which are rich in cholesterol and sphingolipids. ${ }^{25}$ Recently, Dumitru and Gulbins ${ }^{14}$ showed that TRAIL treatment resulted in generation of ceramide at the cell membrane, which clustered with DR5 in a range of cancer cell lines. We found that FLIP silencing (in the absence of TRAIL co-treatment) induced clustering of DR5 in ceramideenriched membrane platforms in NSCLC cells, but not normal lung cells. Furthermore, inhibiting co-localization of DR5 and ceramide or blocking ceramide production abrogated FLIP siRNA-induced apoptosis in NSCLC cells, suggesting that this co-localization is required to induce cell death. Caspase 8 activity has been found to be critical for ASM-regulated, ceramide-mediated FasL-induced Fas clustering and cell death. ${ }^{25}$ We found that only a relatively modest $\sim$ threefold downregulation of procaspase 8 was necessary to block FLIP siRNA-induced apoptosis. Moreover, a $\sim$ threefold upregulation of procaspase 8 in BEAS-2B cells was sufficient to sensitize these otherwise resistant cells to FLIP siRNA and TRAIL. Thus, relatively small changes in the levels of procaspase 8 expression seem to profoundly affect sensitivity to FLIP siRNA and TRAIL, which may explain why the normal lung cell line models, which have lower procaspase 8 expression, are less sensitive to FLIP silencing or TRAIL. This finding may have important clinical relevance given the high percentage of NSCLC tumors that we observed to overexpress procaspase 8.

Numerous determinants of TRAIL sensitivity have been identified, including expression levels of FLIP, XIAP, Bcl-2 family members, TRAIL decoy receptors as well as TRAIL receptor glycosylation. ${ }^{26-33}$ In addition, reduced or absent caspase 8 expression has been shown to result in lack of sensitivity to TRAIL-induced apoptosis in a restricted number of cancers, including neuroblastoma and small-cell lung cancer. ${ }^{12,34}$ However, caspase 8 expression is retained in most cancers and a polymorphism in the caspase 8 promoter that decreases caspase 8 expression has been associated with reduced susceptibility to multiple cancers, including lung cancer. ${ }^{35}$ In this study, we found that procaspase 8 was actually overexpressed in a panel of 20 NSCLCs. The apparent selection for procaspase 8 overexpression in NSCLC is intriguing and suggests that in the presence of FLIP, procaspase 8 may activate proliferative or pro-survival signaling pathways, for example through activation of $\mathrm{NF} \kappa \mathrm{B} .{ }^{36}$ Although the NSCLC cells overexpressed procaspase 8 , we found that constitutive caspase 8 activity was similar in NSCLC and normal lung cells. However, when FLIP was silenced, caspase 8 was activated and apoptosis was induced in the NSCLC cells, but not in the normal lung cells. Collectively, our results suggest that FLIP actively prevents overexpressed procaspase 8 being activated by DR4 and DR5 in NSCLC cells, both constitutively and in the context of chemotherapy/TRAIL treatment. Thus, targeting FLIP may preferentially sensitize NSCLC cells to chemotherapy and TRAIL and may therefore represent a promising therapeutic strategy for NSCLC. Furthermore, tumor procaspase 8 expression may be a useful biomarker for the effectiveness of such strategies.

\section{Materials and Methods}

Reagents. Recombinant human TRAIL was purchased from Calbiochem (Gibbstown, NJ, USA), reconstituted in filter-sterilized PBS/0.1\% bovine serum albumin (BSA) as a $20 \mathrm{ng} / \mathrm{ml}$ stock solution and stored at $-70^{\circ} \mathrm{C}$. Anti-TRAIL neutralizing antibody was obtained from R\&D Systems (Minneapolis, MN, USA). Nystatin was obtained from Sigma, Dorset, UK. Interferon gamma (IFN- $\gamma$ ) was purchased from Calbiochem.

Cell culture. All the cell lines were maintained in $5 \% \mathrm{CO}_{2}$ at $37^{\circ} \mathrm{C}$. $\mathrm{H} 460, \mathrm{H} 157$ and $\mathrm{H} 727$ cells were maintained in DMEM supplemented with $10 \%$ bovine calf serum, $1 \mathrm{mmol} / /$ sodium pyruvate, $2 \mathrm{mmol} / \mathrm{l}$ L-glutamine and $50 \mu \mathrm{g} / \mathrm{ml}$ penicillin/ streptomycin (all from Invitrogen, Paisley, UK). A549 cells were maintained in DMEM supplemented with $10 \%$ bovine calf serum, $2 \mathrm{mmol} / / \mathrm{L}$-glutamine and $50 \mu \mathrm{g} /$ $\mathrm{ml}$ penicillin/streptomycin. 34LU cells were maintained in DMEM supplemented with $10 \%$ bovine calf serum, $2 \mathrm{mmol} / \mathrm{L}$-glutamine, $100 \mu \mathrm{mol} / /$ non-essential amino acids and $50 \mu \mathrm{g} / \mathrm{ml}$ penicillin/streptomycin. BEAS-2B cells were maintained in $\mathrm{F} 12 \mathrm{Ham}$ Medium (Invitrogen) supplemented with $10 \%$ bovine calf serum, $2 \mathrm{mmol} / \mathrm{l}$ L-glutamine, $100 \mu \mathrm{mol} / \mathrm{l}$ non-essential amino acids (Invitrogen) and $50 \mu \mathrm{g} / \mathrm{ml}$ penicillin/streptomycin.

Western blotting. Western Blots were carried out as previously described. ${ }^{18}$ FLIP (NF6; Alexis, San Diego, CA, USA), Caspase 8 (12F5; Alexis) and Poly-ADPRibose-Polymerase-1 (PARP; eBioscience, San Diego, CA, USA) mouse monoclonal antibodies were used in conjunction with a horseradish peroxidaseconjugated sheep anti-mouse secondary antibody (Amersham, Buckinghamshire, UK). Caspase 9, caspase 3 and phospho-STAT1 (Tyr701) (Cell Signalling, Beverly, MA, USA) and DR4 (Calbiochem) rabbit polyclonal antibodies were used in conjunction with a horseradish peroxidase-conjugated sheep anti-rabbit secondary antibody (Amersham). DR5 ( $\mathrm{N}-19)$ goat polyclonal antibody (Santa Cruz Biotechnology, Santa Cruz, CA, USA) was used in conjunction with a horseradish peroxidase-conjugated donkey anti-goat secondary antibody (Santa Cruz). Equal loading was assessed using a $\beta$-tubulin mouse monoclonal primary antibody (Sigma) or $\beta$-actin mouse monoclonal primary antibody (Sigma). For xenograft samples, FLIP was detected using the FLIP (Dave-2; Alexis) rat monoclonal antibody in conjunction with a horseradish peroxidase-conjugated goat anti-rat secondary antibody (Amersham).

Patient samples. The NSCLC patients were all part of an EU Biomarkers Study, and patient consent was received before the surgery. Patients' details are given in Table 1. The patients' tumors were resected at St. James' Hospital, Dublin. Immediately after resection, a consultant pathologist identified the normal and tumor tissues and cut a piece of each. The tissues were then immediately snap frozen in liquid nitrogen. Proteins were extracted using standard protein extraction procedures and western blot analysis carried out as described above.

Flow cytometry. Apoptosis was determined using propidium iodide (PI) staining to evaluate the percentage of cells with DNA content $<2 \mathrm{~N}$ as previously described. ${ }^{18}$ For annexin V/PI analysis, cells were harvested and analyzed according to manufacturer's instructions (BD Biosciences, Oxford, UK). Cell surface expression of death receptors was performed as previously described. ${ }^{18}$ 
siRNA transfections. siRNA duplexes were designed to downregulate both splice variants of FLIP (FT), or to specifically downregulate either the long form (FL) or the short from (FS) of FLIP as previously described. ${ }^{18}$ The non-silencing control (SC) siRNA, caspase 8-targeted (C8), Fas-targeted and DR5-targeted siRNAs were the same as those previously described. ${ }^{18}$ The DR4-targeting siRNA sequence used was CAAACUUCAUGAUCAAUCAdTdT. siRNAs for in vitro transfection were obtained from Dharmacon (Chicago, IL, USA). Modified Stealth siRNAs based on the $\mathrm{FT}$ and $\mathrm{SC}$ sequences were obtained from Invitrogen. siRNA transfections were carried out on sub-confluent cells using OligofectAMINE reagent (Invitrogen) in the H460, A549, H157, 34LU and BEAS-2B cell lines, or using LipofectAMINE 2000 reagent (Invitrogen) in the $\mathrm{H} 727$ cell line, according to manufacturer's instructions.

Quantitative PCR. Total RNA was isolated using the RNA STAT-60 reagent (Biogenesis, Poole, UK) according to the manufacturer's instructions. Reverse transcription of $2 \mu \mathrm{g}$ of RNA was carried out using a Moloney murine leukemia virusbased reverse transcriptase kit (Invitrogen) according to the manufacturer's instructions. Quantitative reverse transcription-PCR amplification was performed in a final volume of $10 \mu \mathrm{l}$ containing $5 \mu \mathrm{l}$ of $2 \times$ SYBR green master mix (Qiagen, Crawley, UK), $4 \mu \mathrm{l}$ of primers $(2 \mu \mathrm{M})$ and $1 \mu \mathrm{l}$ of cDNA using an Opticon DNA Engine Thermal Cycler (Bio-Rad Laboratories, Inc., Waltham, MA, USA). The caspase 8 primers used were: forward: CTGCTGGGGATGGCCACTGTG; reverse: TCGCCTCGAGGACACGCTCTC. The 18S rRNA primers used were: forward: CATTCGTATTGCGCCGCTA; reverse: CGACGGTATCTGATCGTCT. Reaction conditions were: activation at $95^{\circ} \mathrm{C}$ for $10 \mathrm{~min}$; denaturation at $95^{\circ} \mathrm{C}$ for $15 \mathrm{~s}$; annealing at $58.6^{\circ} \mathrm{C}$ for $30 \mathrm{~s}$ and extension at $72^{\circ} \mathrm{C}$ for $1 \mathrm{~min}$. All PCR amplifications were carried out for 40 cycles. Melt curve analysis was used to examine the specificity of an amplified product. Standard curves were generated to quantify the absolute expression levels of each target gene.

Caspase 8 activity assay. The caspase-GLOß 8 assay system was used according to the manufacturer's instructions Promega (Southampton, UK).

Animal model experiments. Female BALB/c nude mice were maintained under sterile and controlled environmental conditions $\left(22^{\circ} \mathrm{C}, 50 \pm 10 \%\right.$ relative humidity, 12-h light/12-h dark cycle and autoclaved bedding), with food and water ad libitum. After a minimum of 1 week of quarantine, mice were included in the protocols. All the experiments were carried out in accordance with the Animals (Scientific Procedures) Act, 1986 under a Project Licence (PPL 2590b) approved by the Department of Health, Social Services and Public Safety, Northern Ireland. To calculate tumor measurement, two axes of the tumors were measured using digital Vernier calipers. Tumor volumes were determined by the following formula: shortest tumor diameter ${ }^{2} \times$ longest tumor diameter $\times 0.5$. For analysis of the effects of FLIP siRNA on xenograft growth, mice were implanted sub-cutaneously on each flank with $2 \times 10^{6} \mathrm{H} 460$ cells using Matrigel. The next day, $1000 \mathrm{pmol}$ of Stealth modified (Invitrogen) non-silencing control (Con) or FLIP-targeted (FLIP) siRNA were injected intratumorally using a 29-gauge insulin syringe (Kendall, Tyco Healthcare, Princeton, NJ, USA). The siRNAs were complexed with Lipofectamine 2000 using Opti-MEM medium. siRNAs were injected on days 1, 3, 6, 8, 10, 13, 15 and 17. To analyze the effects of FLIP siRNA in combination with cisplatin, $2 \times 10^{6}$ $\mathrm{H} 460$ cells were implanted on each flank using Matrigel and the tumors were allowed to reach a volume of approximately $50 \mathrm{~mm}^{3}$ ( Day 6). After xenograft establishment, tumors were directly injected with $1000 \mathrm{pmol}$ Con or FLIP siRNAs thrice weekly, with half the mice receiving cisplatin $(5 \mathrm{mg} / \mathrm{kg}$, intraperitoneal) once a week, for 2 weeks as indicated. Harvested tumors were snap frozen in liquid nitrogen. To extract protein, xenografts were homogenized in radioimmunoprecipitation assay buffer on ice.

Immunostaining of DR5 and ceramide. After treatment, adherent cells were washed with PBS and fixed for 10 min with $4 \%$ paraformaldehyde (Sigma). After three washes with PBS, cells were blocked for 60 min with PBS/3\% BSA. Cells were then washed thrice with PBS $/ 0.2 \%$ BSA and incubated with rabbit anti-DR5 (Calbiochem) and mouse anti-ceramide (MID15B4; Alexis) antibodies, diluted $1: 100$ overnight at $4^{\circ} \mathrm{C}$. After three washes in PBS/0.1\% triton-X (Roche Applied Science, Mannheim, Germany), cells were incubated with Alexa Fluor 594conjugated goat anti-mouse IgM and Alexa Fluor 488-conjugated goat anti-rabbit IgG (Molecular Probes, Eugene, OR, USA) antibodies, diluted $1: 1000$ for $2 \mathrm{~h}$ at room temperature. After five washes with $\mathrm{PBS} / 0.1 \%$ triton- $\mathrm{X}$, slides were mounted using Vectashield containing Dapi (Vector Laboratories, Burlingame, CA, USA).
Images were obtained using a Zeiss Axiovert 200M inverted microscope (Thornwood, NY, USA) using a $\times 63$ oil-immersion objective.

Acknowledgements. This work was supported by Cancer Research UK (TRW, KMM, CL-C, DAF, PGJ, DBL), the Medical Research Council (DBL), Department of Employment and Learning Northern Ireland (KMR, NC).

1. Ashkenazi A, Dixit VM. Death receptors: signaling and modulation. Science 1998; 281: 1305-1308.

2. Chinnaiyan AM, O'Rourke $K$, Tewari M, Dixit VM. FADD, a novel death domain-containing protein, interacts with the death domain of Fas and initiates apoptosis. Cell 1995; 81: 505-512.

3. Bodmer JL, Holler N, Reynard S, Vinciguerra P, Schneider P, Juo P et al. TRAIL receptor-2 signals apoptosis through FADD and caspase-8. Nat Cell Biol 2000; 2: 241-243.

4. Irmler M, Thome M, Hahne M, Schneider P, Hofmann K, Steiner V et al. Inhibition of death receptor signals by cellular FLIP. Nature 1997; 388: 190-195.

5. Micheau O, Thome M, Schneider P, Holler N, Tschopp J, Nicholson DW et al. The long form of FLIP is an activator of caspase-8 at the Fas death-inducing signaling complex. J Biol Chem 2002; 277: 45162-45171.

6. Zhou XD, Yu JP, Liu J, Luo HS, Chen HX, Yu HG. Overexpression of cellular FLICEinhibitory protein (FLIP) in gastric adenocarcinoma. Clin Sci (Lond) 2004; 106: 397-405.

7. Ryu BK, Lee MG, Chi SG, Kim YW, Park JH. Increased expression of cFLIP(L) in colonic adenocarcinoma. J Pathol 2001; 194: 15-19.

8. Remmelink M, Mijatovic T, Gustin A, Mathieu A, Rombaut K, Kiss R et al. Identification by means of CDNA microarray analyses of gene expression modifications in squamous nonsmall cell lung cancers as compared to normal bronchial epithelial tissue. Int J Oncol 2005; 26: $247-258$.

9. Frese S, Brunner T, Gugger M, Uduehi A, Schmid RA. Enhancement of Apo2L/TRAIL (tumor necrosis factor-related apoptosis-inducing ligand)-induced apoptosis in non-small cell lung cancer cell lines by chemotherapeutic agents without correlation to the expression level of cellular protease caspase-8 inhibitory protein. J Thorac Cardiovasc Surg 2002; 123: 168-174.

10. Maione $P$, Gridelli $C$, Troiani T, Ciardiello F. Combining targeted therapies and drugs with multiple targets in the treatment of NSCLC. Oncologist 2006; 11: 274-284.

11. Cooper WA, Kohonen-Corish MR, Zhuang L, McCaughan B, Kennedy C, Screaton G et al. Role and prognostic significance of tumor necrosis factor-related apoptosis-inducing ligand death receptor DR5 in nonsmall-cell lung cancer and precursor lesions. Cancer 2008; 113: 135-142.

12. Hopkins-Donaldson S, Ziegler A, Kurtz S, Bigosch C, Kandioler D, Ludwig C et al. Silencing of death receptor and caspase-8 expression in small cell lung carcinoma cell lines and tumors by DNA methylation. Cell Death Differ 2003; 10: 356-364.

13. Shivapurkar N, Toyooka S, Eby MT, Huang CX, Sathyanarayana UG, Cunningham HT et al. Differential inactivation of caspase-8 in lung cancers. Cancer Biol Ther 2002; 1 : 65-69.

14. Dumitru CA, Gulbins E. TRAIL activates acid sphingomyelinase via a redox mechanism and releases ceramide to trigger apoptosis. Oncogene 2006; 25: 5612-5625.

15. Delmas D, Rebe C, Micheau O, Athias A, Gambert P, Grazide $S$ et al. Redistribution of CD95, DR4 and DR5 in rafts accounts for the synergistic toxicity of resveratrol and death receptor ligands in colon carcinoma cells. Oncogene 2004; 23: 8979-8986.

16. Li H, Zhu H, Xu CJ, Yuan J. Cleavage of BID by caspase 8 mediates the mitochondrial damage in the Fas pathway of apoptosis. Cell 1998; 94: 491-501.

17. Scaffidi C, Fulda S, Srinivasan A, Friesen C, Li F, Tomaselli KJ et al. Two CD95 (APO-1/ Fas) signaling pathways. EMBO J 1998; 17: 1675-1687.

18. Wilson TR, McLaughlin KM, McEwan M, Sakai H, Rogers KM, Redmond KM et al. c-FLIP: a key regulator of colorectal cancer cell death. Cancer Res 2007; 67: 5754-5762.

19. Ashkenazi A, Pai RC, Fong S, Leung S, Lawrence DA, Marsters SA et al. Safety and antitumor activity of recombinant soluble Apo2 ligand. J Clin Invest 1999; 104: 155-162.

20. Johnstone RW, Frew AJ, Smyth MJ. The TRAIL apoptotic pathway in cancer onset, progression and therapy. Nat Rev Cancer 2008; 8: 782-798.

21. Schimmer AD, Thomas MP, Hurren R, Gronda M, Pellecchia M, Pond GR et al. Identification of small molecules that sensitize resistant tumor cells to tumor necrosis factorfamily death receptors. Cancer Res 2006; 66: 2367-2375.

22. Abedini MR, Qiu Q, Yan X, Tsang BK. Possible role of FLICE-like inhibitory protein (FLIP) in chemoresistant ovarian cancer cells in vitro. Oncogene 2004; 23: 6997-7004.

23. Kamarajan P, Sun NK, Chao CC. Up-regulation of FLIP in cisplatin-selected HeLa cells causes cross-resistance to CD95/Fas death signalling. Biochem J 2003; 376: 253-260.

24. Longley DB, Wilson TR, McEwan M, Allen WL, McDermott U, Galligan L et al. c-FLIP inhibits chemotherapy-induced colorectal cancer cell death. Oncogene 2006; 25: 838-848.

25. Grassme H, Cremesti A, Kolesnick R, Gulbins E. Ceramide-mediated clustering is required for CD95-DISC formation. Oncogene 2003; 22: 5457-5470.

26. Marsters SA, Sheridan JP, Pitti RM, Huang A, Skubatch M, Baldwin D et al. A novel receptor for Apo2L/TRAIL contains a truncated death domain. Curr Biol 1997; 7: 1003-1006. 
27. Fulda S, Meyer E, Debatin KM. Inhibition of TRAIL-induced apoptosis by $\mathrm{Bcl}-2$ overexpression. Oncogene 2002; 21: 2283-2294.

28. Taniai M, Grambihler A, Higuchi H, Werneburg N, Bronk SF, Farrugia DJ et al. Mcl-1 mediates tumor necrosis factor-related apoptosis-inducing ligand resistance in human cholangiocarcinoma cells. Cancer Res 2004; 64: 3517-3524.

29. Ndozangue-Touriguine O, Sebbagh M, Merino D, Micheau O, Bertoglio J, Breard J. A mitochondrial block and expression of XIAP lead to resistance to TRAIL-induced apoptosis during progression to metastasis of a colon carcinoma. Oncogene 2008; 27: 6012-6022.

30. Vogler M, Durr K, Jovanovic M, Debatin KM, Fulda S. Regulation of TRAILinduced apoptosis by XIAP in pancreatic carcinoma cells. Oncogene 2007; 26: 248-257.

31. Dolcet X, Llobet D, Pallares J, Rue M, Comella JX, Matias-Guiu X. FLIP is frequently expressed in endometrial carcinoma and has a role in resistance to TRAlL-induced apoptosis. Lab Invest 2005; 85: 885-894.
32. Mathas S, Lietz A, Anagnostopoulos I, Hummel F, Wiesner B, Janz M et al, c-FLIP mediates resistance of Hodgkin/Reed-Sternberg cells to death receptor-induced apoptosis. $J$ Exp Med 2004; 199: 1041-1052.

33. Wagner KW, Punnoose EA, Januario T, Lawrence DA, Pitti RM, Lancaster K et al. Deathreceptor O-glycosylation controls tumor-cell sensitivity to the proapoptotic ligand Apo2L/ TRAIL. Nat Med 2007; 13: 1070-1077.

34. Eggert A, Grotzer MA, Zuzak TJ, Wiewrodt BR, Ho R, Ikegaki N et al. Resistance to tumor necrosis factor-related apoptosis-inducing ligand (TRAIL)-induced apoptosis in neuroblastoma cells correlates with a loss of caspase-8 expression. Cancer Res 2001; 61: 1314-1319.

35. Sun T, Gao Y, Tan W, Ma S, Shi Y, Yao J et al. A six-nucleotide insertion-deletion polymorphism in the CASP8 promoter is associated with susceptibility to multiple cancers. Nat Genet 2007; 39: 605-613.

36. Kataoka T, Budd RC, Holler N, Thome M, Martinon F, Irmler M et al. The caspase-8 inhibitor FLIP promotes activation of NF-kappaB and Erk signaling pathways. Curr Biol 2000; 10: 640-648.

Supplementary Information accompanies the paper on Cell Death and Differentiation website (http://www.nature.com/cdd) 